\title{
Numerical Approach to Predicting Thermodynamic Properties of Ternary Al-Ni-Pt Alloys
}

\author{
M. Zagula-Yavorska*, J. Romanowska, S. Kotowski and J. Sieniawski \\ Departament of Materials Science, Rzeszów University of Technology, \\ Powstańców Warszawy 12, 35-959 Rzeszów, Poland
}

(Received August 18, 2014; revised version March 9, 2015; in final form April 28, 2015)

\begin{abstract}
Thermodynamic properties of ternary Al-Ni-Pt system, such as ${ }^{e x} G_{\mathrm{AlNiPt}}, \mu_{\mathrm{Al}(\mathrm{AlNiPt})}, \mu_{\mathrm{Ni}(\mathrm{AlNiPt})}$, and $\mu_{\mathrm{Pt} \text { (AlNiPt) }}$ at $1373 \mathrm{~K}$ were predicted on the basis of thermodynamic properties of binary systems included in the investigated ternary system. The idea of predicting ${ }^{e x} G_{\mathrm{AlNiPt}}$ values was regarded as calculation of values of ${ }^{\text {ex }} G$ function inside a certain area (a Gibbs triangle) unless all boundary conditions, that is values of ${ }^{\text {ex }} G$ on all legs of the triangle are known ( $\left.{ }^{\mathrm{ex}} G_{\mathrm{AlNi}},{ }^{\mathrm{ex}} G_{\mathrm{AlPt}},{ }^{\mathrm{ex}} G_{\mathrm{NiPt}}\right)$. This approach is contrary to finding the function value outside a certain area, if the function value inside this area is known. ${ }^{e x} \mathrm{G}$ and $L_{i j k}$ ternary interaction parameters in the Muggianu extension of the Redlich-Kister formalism are calculated numerically using the Mathematica program. The accepted values of the third component concentration $x_{x}$ differed from 0.01 to 0.1 mol fraction. Values of $L$ parameters in the Redlich-Kister formula vary for different $x_{x}$ values, the ${ }^{0} L_{\text {AlNiPt }}$ value in particular. Values of thermodynamic functions: ${ }^{\mathrm{ex}} G_{\mathrm{AlNiPt}}, \mu_{\mathrm{Al}(\mathrm{AlNiPt})}, \mu_{\mathrm{Ni}(\mathrm{AlNiPt})}$ and $\mu_{\mathrm{Pt}(\mathrm{AlNiPt})}$ do not differ significantly for different $x_{x}$ values. The choice of $x_{x}$ value does not influence the accuracy of calculations.
\end{abstract}

DOI: $10.12693 /$ APhysPolA.127.1573

PACS: $02.60 . \mathrm{Cb}, 05.70 . \mathrm{Ce}$

\section{Introduction}

Aluminide diffusion coatings are widely used for high temperature oxidation and hot corrosion protection of turbine blades used in engine hot sections [1]. These blades are made of nickel-based superalloys [2, 3]. However, aluminide coatings do not fulfill the requirements of long term oxidation resistance at high temperature. Modification of aluminide coatings by platinum is the most effective way to increase their oxidation resistance [4-12]. Coatings are formed in a diffusion process. The information about this process is essential for predicting and influencing the structure and properties of the coatings. Simulation of the diffusion of aluminum, platinum, and nickel requires thorough thermodynamic descriptions of the $\mathrm{Al}-\mathrm{Ni}-\mathrm{Pt}$ system and estimation values of chemical potentials of diffusive elements, $\mu_{\mathrm{Al}(\mathrm{AlNiPt})}, \mu_{\mathrm{Ni}(\mathrm{AlNiPt})}$, and $\mu_{\mathrm{Pt}(\mathrm{AlNiPt})}$. Unfortunately, there is no experimental data of the thermodynamic functions of the $\mathrm{Al}-\mathrm{Ni}-\mathrm{Pt}$ system. Nevertheless, there are numerous methods of modeling thermodynamic properties and calculations of phase diagrams in complex systems on the basis of thermodynamic properties and phase diagrams of binary alloys constituting the complex system. One of them is a semi-empirical approach, referred as Calphad method [2, 3, 13]. It is a combination of experimental observation and theoretical modeling and depends on the quality of available experimental data. The basic mathematical method is a minimization of the Gibbs energy of the system for a given temperature, pressure and overall composition. This approach is common to all currently available software packages

* corresponding author; e-mail: yavorska@prz.edu.pl for the modeling of thermodynamic properties and phase diagrams of multicomponent systems [13].

In this paper a numerical approach to modeling ternary $\mathrm{Al}-\mathrm{Ni}$-Pt system on the basis of thermodynamic properties of binary systems included in the investigated ternary system is applied. The idea of predicting ${ }^{\text {ex }} G_{i j k}$ values is regarded as calculation values of ${ }^{\mathrm{ex}} G_{i j k}$ function inside a certain area (a Gibbs triangle) unless all boundary conditions, that is values of ${ }^{\mathrm{ex}} G$ on all sides of the triangle, are known $\left({ }^{\mathrm{ex}} G_{i j},{ }^{\mathrm{ex}} G_{i k},{ }^{\mathrm{ex}} G_{j k}\right)$. This approach is contrary to finding a function value outside a certain area, if the function value inside this area is known (this issue is well known in mathematics). In this approach, values of excess Gibbs functions for all concentrations of binary alloys are taken into consideration, not only the selected ones and there is no problem with choosing binary mole fractions and proper weighting, unlike in geometrical models [14]. In this approach, weighting of each mole fraction is the same. This model was successfully applied to many alloys $(\mathrm{Bi}-\mathrm{Cu}-\mathrm{Ni}, \mathrm{Cu}-\mathrm{Sn}-\mathrm{Zn}, \mathrm{Ag}-\mathrm{Au}-$ $\mathrm{Bi}$, In-Sn-Zn, Cu-Fe-Sn, Al-Ni-Pd, Al-Ni-Hf) [13, 1517] and the results are similar to the values obtained by the Calphad method.

\section{Calculations}

The excess Gibbs energy ${ }^{\mathrm{ex}} G_{i j k}$ describes the influence of non-ideal mixing behavior on the thermodynamic properties of a solution phase. The Muggianu [18] extension of the Redlich-Kister formalism [19] is a widely accepted description of the excess Gibbs energy

$$
\begin{aligned}
{ }^{\mathrm{ex}} G^{\varphi} & =\sum_{i \neq j}^{n} x_{i} x_{j} \sum_{z=0}^{m}{ }^{z} L_{i j}^{\varphi}\left(x_{i}-x_{j}\right)^{z} \\
+ & \sum_{i \neq j \neq k}^{n} x_{i} x_{j} x_{k} L_{i j k}^{\varphi},
\end{aligned}
$$


where ${ }^{z} L_{i j}^{\varphi}$ are binary and $L_{i j k}^{\varphi}$ ternary temperature dependent interaction parameters optimized on the basis of the available thermodynamic and phase diagram data.

$$
L_{i j k}^{\varphi}=x_{i}{ }^{0} L^{\varphi} x_{i j k}+x_{j}{ }^{1} L_{i j k}^{\varphi}+x_{k}{ }^{2} L_{i j k}^{\varphi} .
$$

Binary systems are usually well investigated, therefore values of ${ }^{z} L_{i j}^{\varphi}$ parameters are known, but not many ternary alloys have been investigated, so values of $L_{i j k}^{\varphi}$ parameters for many systems are unknown. Unless the formula (1) and ${ }^{z} L_{i j}^{\varphi}$ parameters are known, the idea of calculating $L_{i j k}^{\varphi}$ parameters can be regarded as the solution of Eq. (2), when all boundary conditions (binary $i j$ alloys) are known. The approach proposed in this paper is as follows: if all boundary conditions, that is ${ }^{\operatorname{ex}} G$ values on all sides of the Gibbs triangle $\left({ }^{\mathrm{ex}} G_{i j},{ }^{\mathrm{ex}} G_{i k},{ }^{\mathrm{ex}} G_{j k}\right.$ ) (Fig. 1) are known, a value inside the triangle ( $\left.{ }^{\mathrm{ex}} G_{i j k}\right)$ can be found.

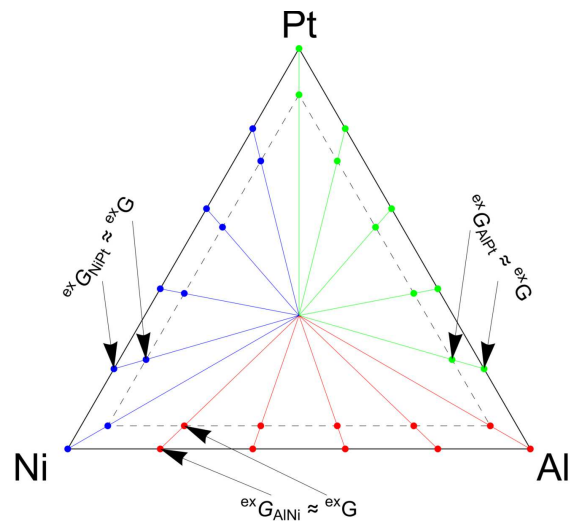

Fig. 1. The Gibbs triangle.

Calculations were performed using the Mathematica program. First, ${ }^{\text {ex }} G$ values on all legs of the triangle were calculated and the concentration of the third component was 0 . Next, an assumption was made that ${ }^{\mathrm{ex}} G$ value on the leg of the triangle and for the small concentration of the third component $x_{x}$ was the same. $L_{i j k}$ were calculated on the basis of this assumption. The concentration of the third component $x_{x}$ varied from 0.01 to $0.1 \mathrm{~mol}$ fraction. In other words, ${ }^{\text {ex }} G$ value for each point of the Gibbs triangle (the bold line) and for the corresponding point of the inner triangle (the dotted line) (see Fig. 1) was assumed to be the same. The concentration of the third component $x_{x}$ represents the distance between the bold and the dotted lines.

$$
\begin{aligned}
& { }^{\mathrm{ex}} G_{i j}={ }^{\mathrm{ex}} G_{i j k} \text { for } x_{i}=0.01, \\
& { }^{\mathrm{ex}} G_{i k}={ }^{\mathrm{ex}} G_{i j k} \text { for } x_{\mathrm{j}}=0.01, \\
& { }^{\mathrm{ex}} G_{j k}={ }^{\text {ex }} G_{i j k} \text { for } x_{\mathrm{k}}=0.01 .
\end{aligned}
$$

$L_{i j k}$ parameters were calculated numerically on the basis of this assumption using the Mathematica program. In the case of presented calculations, case $i, j$ and $k$ denote $\mathrm{Al}, \mathrm{Ni}$ and $\mathrm{Pt}$, respectively.

Thermodynamic parameters for binary alloys ${ }^{z} L_{i j}^{\varphi}$, ${ }^{z} L_{i k}^{\varphi},{ }^{z} L_{j k}^{\varphi}$ (formula (1)) were accepted from Huang and Chang [20] for Al-Ni, Wu and Jin [1] for Al-Pt and $\mathrm{Lu}$ et al. [12] for $\mathrm{Ni}-\mathrm{Pt}$ systems.

$$
\begin{aligned}
& L_{\mathrm{Al}, \mathrm{Ni}}=168292+16 T+32712\left(x_{\mathrm{Al}}-x_{\mathrm{Ni}}\right) \\
& \quad+(7998+35 T)\left(x_{\mathrm{Al}}-x_{\mathrm{Ni}}\right)^{2} \\
& L_{\mathrm{Al}, \mathrm{Pt}}=-264447+(102729-8.57 T)\left(x_{\mathrm{Al}}-x_{\mathrm{Zr}}\right) \\
& L_{\mathrm{Ni}, \mathrm{Pt}}=-5000 .
\end{aligned}
$$

As a result of calculations the following value of ternary $L_{i j k}$ parameter for $1373 \mathrm{~K}$ was obtained on the basis of Eq. (2):

$$
\begin{aligned}
& L_{\mathrm{Al}, \mathrm{Ni}, \mathrm{Pt}}= \\
& \quad-1.2 \times 10^{-} 5 x_{\mathrm{Al}}+9.9 \times 10^{5} x_{\mathrm{Ni}}+7.7 \times 10^{5} x_{\mathrm{Pt}} .
\end{aligned}
$$

In order to check how much the choice of the $x_{x}$ value influences the values of $L$ parameters and excess Gibbs energy calculated on the basis on these parameters, analogous calculations were performed for the $x_{x}$ values 0.01 , 0.05 , and 0.09. Results of calculations are presented in Table (at the end) and Figs. 2-7. Although values of $L$ parameters change with the $x_{x}$ value, especially the ${ }^{0} L_{\mathrm{AlNiPt}}$ value, the final results, that is the excess Gibbs energy does not change significantly.
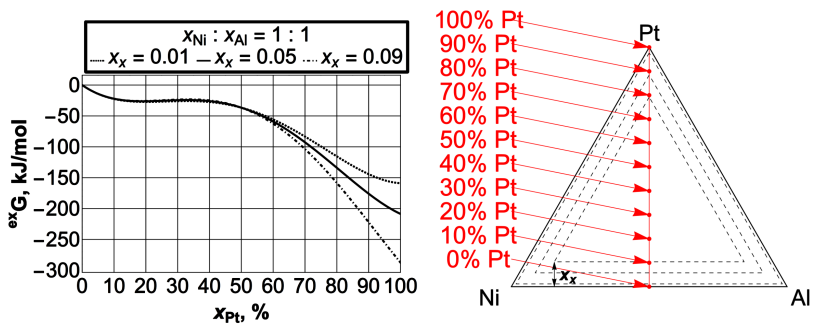

Fig. 2. ${ }^{\mathrm{ex}} G_{\mathrm{AlNiPt}}$ for $x_{\mathrm{Ni}}: x_{\mathrm{Al}}=1: 1$ for different $x_{\mathrm{Pt}}$ values (left) and cross-section (right).
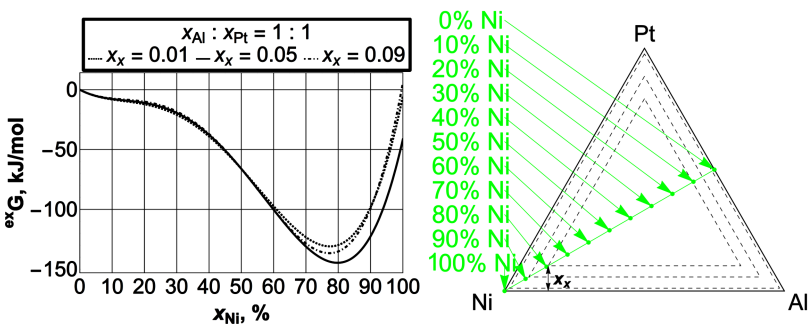

Fig. 3. ${ }^{\text {ex }} G_{\mathrm{AlNiPt}}$ for $x_{\mathrm{Al}}: x_{\mathrm{Pt}}=1: 1$ for different $x_{\mathrm{Ni}}$ values (left) and cross-section (right).
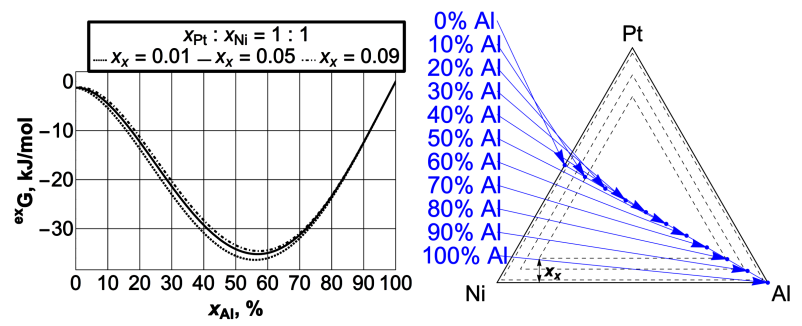

Fig. 4. ${ }^{\text {ex }} G_{\mathrm{AlNiPt}}$ for $x_{\mathrm{Pt}}: x_{\mathrm{Ni}}=1: 1$ for different $x_{\mathrm{Al}}$ values (left) and cross-section (right).

Values of chemical potentials of platinum, nickel and aluminium at $1373 \mathrm{~K}$ were derived from the excess Gibbs energy according to the formulae (10)-(12) [21]. Results of calculations are presented in Figs. 5-7. 


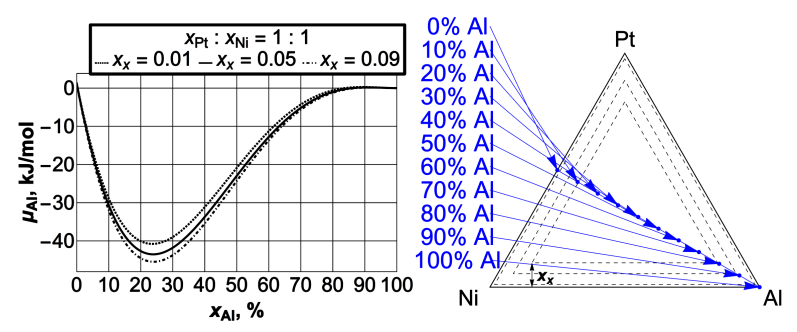

Fig. 5. Values of aluminum chemical potential in Al$\mathrm{Ni}-\mathrm{Pt}$ alloys (left) and cross-section (right).

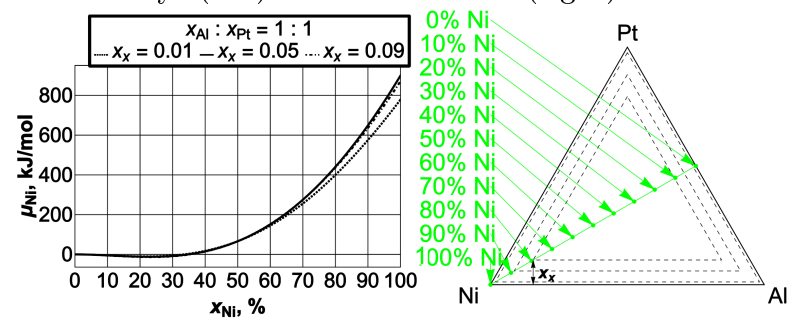

Fig. 6. Values of nickel chemical potential in $\mathrm{Al}-\mathrm{Ni}-\mathrm{Pt}$ alloys (left) and cross-section (right).

$$
\begin{gathered}
\mu_{\mathrm{Al}}={ }^{\mathrm{ex}} G-x_{\mathrm{Ni}} \frac{\partial^{\mathrm{ex}} G}{\partial x_{\mathrm{Ni}}}-x_{\mathrm{Pt}} \frac{\partial^{\mathrm{ex}} G}{\partial x_{\mathrm{Pt}}}= \\
5000 x_{\mathrm{Ni}} x_{\mathrm{Pt}}+x_{\mathrm{Al}}^{2} x_{\mathrm{Ni}}\left(80114 x_{\mathrm{Ni}}+116703.337375 x_{\mathrm{Pt}}\right) \\
+x_{\mathrm{Al}}\left(-80114 x_{\mathrm{Ni}}^{3}+x_{\mathrm{Ni}}^{2}\left(32712-1977166.509368 x_{\mathrm{Pt}}\right)\right. \\
\left.+90962.34 x_{\mathrm{Pt}}^{2}-1543546.046419 x_{\mathrm{Ni}} x_{\mathrm{Pt}}^{2}\right), \\
\mu_{\mathrm{Ni}}={ }^{\mathrm{ex}} G-x_{\mathrm{Al}} \frac{\partial^{\mathrm{ex}} G}{\partial x_{\mathrm{Al}}}-x_{\mathrm{Pt}} \frac{\partial^{\mathrm{ex}} G}{\partial x_{\mathrm{Pt}}}=x_{\mathrm{Al}}\left(-80114 x_{\mathrm{Al}}^{2} x_{\mathrm{Ni}}\right. \\
+x_{\mathrm{Pt}}\left(264446.89-988583.254684 x_{\mathrm{Ni}}^{2}+\right. \\
\left.+181924.68 x_{\mathrm{Pt}}-1543546.046419 x_{\mathrm{Ni}} x_{\mathrm{Pt}}\right) \\
+x_{\mathrm{Al}}\left(80114 x_{\mathrm{Ni}}^{2}-181924.68 x_{\mathrm{Pt}}\right. \\
\left.\left.+x_{\mathrm{Ni}}\left(-32712+233406.674749 x_{\mathrm{Pt}}\right)\right)\right), \\
\mu_{\mathrm{Pt}}={ }^{\mathrm{ex}} G-x_{\mathrm{Al}} \frac{\partial^{\mathrm{ex}} G}{\partial x_{\mathrm{Al}}}-x_{\mathrm{Ni}} \frac{\partial^{\mathrm{ex}} G}{\partial x_{\mathrm{Ni}}}=-120171\left(x_{\mathrm{Al}}^{3} x_{\mathrm{Ni}}\right. \\
+x_{\mathrm{Al}}^{2}\left(-2 x_{\mathrm{Ni}}^{2}+x_{\mathrm{Ni}}\left(0.544424-1.942288 x_{\mathrm{Pt}}\right)\right. \\
\left.+0.756941 x_{\mathrm{Pt}}\right)+x_{\mathrm{Al}} x_{\mathrm{Ni}}\left(-1.217632+x_{\mathrm{Ni}}^{2}\right. \\
\left.\left.+6.422290 x_{\mathrm{Pt}}^{2}+x_{\mathrm{Ni}}\left(-0.544424+16.452942 x_{\mathrm{Pt}}\right)\right)\right) .
\end{gathered}
$$

\section{Conclusions}

Values of excess Gibbs energy and chemical potentials of aluminum, nickel, and platinum in ternary $\mathrm{Al}-$ $\mathrm{Ni}-\mathrm{Pt}$ alloys at $1373 \mathrm{~K}$ were predicted numerically for three cross-sections $\left(x_{\mathrm{Al}}: x_{\mathrm{Ni}}=1: 1, \quad x_{\mathrm{Pt}}: x_{\mathrm{Ni}}=1: 1\right.$, $x_{\mathrm{Pt}}: x_{\mathrm{Al}}=1: 1$ and for alloys of the following contents: $\left(x_{\mathrm{Al}}=1 / 3, x_{\mathrm{Ni}}=1 / 3, x_{\mathrm{Pt}}=1 / 3, x_{\mathrm{Al}}=2 / 5, x_{\mathrm{Ni}}=2 / 5\right.$, $x_{\mathrm{Pt}}=1 / 5$, and $\left.x_{\mathrm{Al}}=1 / 10, x_{\mathrm{Ni}}=4 / 5, x_{\mathrm{Pt}}=1 / 10\right)$. The obtained values of the excess Gibbs energy do not change significantly with the change of the predicting procedure, namely the accepted $x_{x}$ value. The results obtained in this work, that is values of chemical poten-

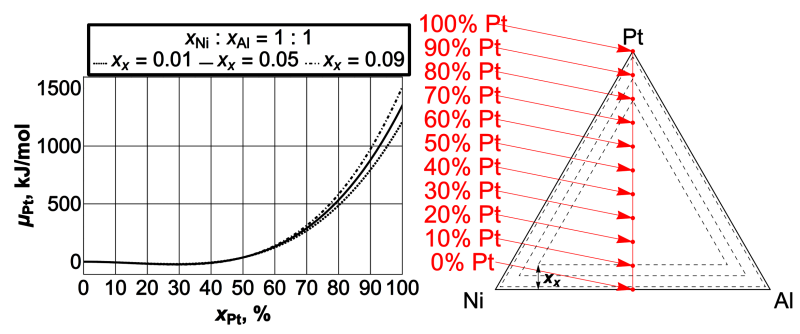

Fig. 7. Values of platinum chemical potential in $\mathrm{Al}-$ $\mathrm{Ni}-\mathrm{Pt}$ alloys (left) and cross-section (right).

tials will be used to model the diffusion process in the platinum modified aluminide coatings.

\section{References}

[1] K. Wu, Z. Jin, J. Phase Equil. 21, 221 (2000).

[2] S. Petronic, S. Drecun-Nesic, A. Milosavljevic, A. Sedmak, M. Popovic, A. Kovacevic, Acta Phys. Pol. A 116, 550 (2009)

[3] A. Milosavljevic, S. Petronic, M. Sreckovic, A. Kovacevic, A. Krmpot, K. Kovacevic, Acta Phys. Pol. A 116, 553 (2009).

[4] J. Angenete, K. Stiller, Mater. Sci. Eng. A 316, 182 (2001).

[5] A.L. Purvis, B.M. Warnes, Surf. Coat. Technol. 146-147, 1 (2001).

[6] V.K. Tolpygo, D.R. Clarke, Acta Mater. 48, 3283 (2000).

[7] D. Das, V. Singh, S.V. Joshi, Oxidat. Met. 57, 245 (2002).

[8] D. Das, M. Roy, V. Singh, S. Joshi, Mater. Sci. Technol. 15, 1199 (1999).

[9] G.R. Krishna, D.K. Das, V. Singh, S.V. Joshi, Mater. Sci. Eng. A 251, 40 (1998).

[10] Y.Q. Wang, G. Sayre, Surf. Coat. Technol. 203, 1264 (2009)

[11] M. Zagula-Yavorska, J. Sieniawski，JMEPEG 23, 918 (2014).

[12] X. Lu, B. Sundman, J. Agren, Calphad 33, 450 (2009).

[13] J. Romanowska, Inżynieria Materiałowa 32, 929 (2011) (in Polish).

[14] R. Ganesan, S. Vana Varamban, Calphad 24, 509 (1997).

[15] J. Romanowska, Wulfenia J. 20, 2 (2013).

[16] M. Zagula-Yavorska, J. Romanowska, S. Kotowski, J. Sieniawski, High Temperature Materials and Processes.

[17] J. Romanowska, S. Kotowski, M. Zagula-Yavorska, Int. Conf. Comput. Meth. Sci. Eng. (ICCMSE 2014), AIP Conference Proceedings vol. 1618, 2014, p. 986.

[18] Y. Muggianu, M. Gambio, J. Bros, J. Chim. Phys. 72, 83 (1975).

[19] O. Redlich, T. Kister, Ind. Eng. Chem. 40, 345 (1948).

[20] W. Huang, Y.A. Chang, Intermetallics 6, 487 (1998).

[21] M. Hillert, Thermodynamics of Phase Equilibria and Transformations, Royal Institute of Technology, Stockholm 1995. 


\section{TABLE}

The calculated values of $L$ parameters and the excess Gibbs energy.

\begin{tabular}{c|c|c|c|c|c|c}
\hline \hline$x_{x}$ & ${ }^{0} L_{\mathrm{AlNiPt}}$ & ${ }^{1} L_{\mathrm{AlNiPt}}$ & ${ }^{2} L_{\mathrm{AlNiPt}}$ & $\begin{array}{c}{ }^{\mathrm{ex}} G_{\mathrm{AlNiPt}} \\
x_{\mathrm{Al}}=x_{\mathrm{Ni}}= \\
x_{\mathrm{Pt}}=1 / 3\end{array}$ & $\begin{array}{c}{ }^{\mathrm{ex}} G_{\mathrm{AlNiPt}} \\
x_{\mathrm{Al}}=x_{\mathrm{Ni}}=2 / 5, \\
x_{\mathrm{Pt}}=1 / 5\end{array}$ & $\begin{array}{c}{ }^{\mathrm{ex}} G_{\mathrm{AlNiPt}} \\
x_{\mathrm{Al}}=x_{\mathrm{Pt}}=1 / 10, \\
x_{\mathrm{Ni}}=4 / 5\end{array}$ \\
\hline 0.01 & $-1.2 \times 10^{5}$ & $9.9 \times 10^{5}$ & $7.7 \times 10^{5}$ & $-2.6 \times 10^{4}$ & $-2.7 \times 10^{4}$ & $-8.2 \times 10^{3}$ \\
0.02 & $-1.0 \times 10^{5}$ & $1.0 \times 10^{6}$ & $7.9 \times 10^{5}$ & $-2.5 \times 10^{4}$ & $-2.7 \times 10^{4}$ & $-8.1 \times 10^{3}$ \\
0.03 & $-9.3 \times 10^{4}$ & $1.0 \times 10^{6}$ & $8.0 \times 10^{5}$ & $-2.5 \times 10^{4}$ & $-2.7 \times 10^{4}$ & $-8.0 \times 10^{3}$ \\
0.04 & $-8.3 \times 10^{4}$ & $1.0 \times 10^{6}$ & $8.1 \times 10^{5}$ & $-2.5 \times 10^{4}$ & $-2.6 \times 10^{4}$ & $-7.9 \times 10^{3}$ \\
0.05 & $-7.4 \times 10^{4}$ & $1.0 \times 10^{6}$ & $8.1 \times 10^{5}$ & $-2.4 \times 10^{4}$ & $-2.6 \times 10^{4}$ & $-7.8 \times 10^{3}$ \\
0.06 & $-6.6 \times 10^{4}$ & $1.1 \times 10^{6}$ & $8.2 \times 10^{5}$ & $-2.4 \times 10^{4}$ & $-2.6 \times 10^{4}$ & $-7.7 \times 10^{3}$ \\
0.07 & $-6.1 \times 10^{4}$ & $1.1 \times 10^{6}$ & $8.2 \times 10^{5}$ & $-2.4 \times 10^{4}$ & $-2.5 \times 10^{4}$ & $-7.6 \times 10^{3}$ \\
0.08 & $-5.8 \times 10^{4}$ & $1.1 \times 10^{6}$ & $8.2 \times 10^{5}$ & $-2.3 \times 10^{4}$ & $-2.5 \times 10^{4}$ & $-7.5 \times 10^{3}$ \\
0.09 & $-5.8 \times 10^{4}$ & $1.1 \times 10^{6}$ & $8.2 \times 10^{5}$ & $-2.3 \times 10^{4}$ & $-2.5 \times 10^{4}$ & $-7.3 \times 10^{3}$ \\
0.1 & $-6.2 \times 10^{4}$ & $1.1 \times 10^{6}$ & $8.1 \times 10^{5}$ & $-2.3 \times 10^{4}$ & $-2.5 \times 10^{4}$ & $-7.2 \times 10^{3}$
\end{tabular}

